\title{
The significance of intra-abdominal pressure in neurosurgery and neurological diseases: a narrative review and a conceptual proposal
}

\author{
Paul R. A. M. Depauw ${ }^{1,2} \cdot$ Rob J. M. Groen ${ }^{3} \cdot$ Johannes Van Loon $^{4}$ • Wilco C. Peul ${ }^{5}$ - Manu L. N. G. Malbrain ${ }^{6,7}$ • \\ Jan J. De Waele ${ }^{8}$
}

Received: 14 September 2018 / Accepted: 3 March 2019 / Published online: 25 March 2019

(C) The Author(s) 2019

\begin{abstract}
Intra-abdominal pressure (IAP) is a physiological parameter that has gained considerable attention during the last few decades. The incidence of complications arising from increased IAP, known as intra-abdominal hypertension (IAH) or abdominal compartment syndrome in critically ill patients, is high and its impact is significant. The effects of IAP in neurological conditions and during surgical procedures are largely unexplored. IAP also appears to be relevant during neurosurgical procedures (spine and brain) in the prone position, and in selected cases, IAH may affect cerebrospinal fluid drainage after a ventriculoperitoneal shunt operation. Furthermore, raised IAP is one of the contributors to intracranial hypertension in patients with morbid obesity. In traumatic brain injury, case reports described how abdominal decompression lowers intracerebral pressure. The anatomical substrate for transmission of the IAP to the brain and venous system of the spine is the extradural neural axis compartment; the first reports of this phenomenon can be found in anatomical studies of the sixteenth century. In this review, we summarize the available knowledge on how IAP impacts the cerebrospinal venous system and the jugular venous system via two pathways, and we discuss the implications for neurosurgical procedures as well as the relevance of IAH in neurological disorders.
\end{abstract}

Keywords Vertebral venous system, VVS · Intra-abdominal pressure, IAP · Intra-abdominal hypertension, IAH · Prone position · Idiopathic intracranial hypertension, IIH · Hydrocephalus · Traumatic brain injury, TBI · Prone position · Cerebrospinal venous system, CSVS · Extradural neural axis compartment, EDNAC

\section{Introduction}

Increased intra-abdominal pressure (IAP) is recognized as a significant contributor to organ dysfunction in many critically ill patients. Although it primarily has been studied in surgical

This article is part of the Topical Collection on Neurosurgery general

Paul R. A. M. Depauw

p.depauw@etz.nl

1 Department of Neurosurgery, Elisabeth Tweesteden Hospital (ETZ), Tilburg, The Netherlands

2 Elisabeth Tweesteden Hospital, Hilvarenbeekseweg 60, 5022 GC Tilburg, The Netherlands

3 Department of Neurosurgery, University Medical Center Groningen, University of Groningen, Groningen, The Netherlands

4 Department of Neurosurgery, University Hospitals Leuven, KU Leuven, Leuven, Belgium
ICU patients suffering from abdominal catastrophes such as abdominal trauma, peritonitis, and pancreatitis, it has also been associated with massive fluid resuscitation.

IAP is defined as the steady-state pressure within the abdominal cavity. Under physiological conditions, values of up
5 Department of Neurosurgery, Leiden University Medical Center (LUMC) and The Hague Medical Center (HMC+),

Leiden, The Netherlands

6 Intensive Care Unit, University Hospital Brussels (UZB), Jette, Belgium

7 Faculty of Medicine and Pharmacy, Vrije Universiteit Brussel (VUB), Brussels, Belgium

8 Department of Critical Care Medicine, Ghent University Hospital, Ghent, Belgium 
to $5 \mathrm{mmHg}$ are considered normal in adults [14]. IAP varies inversely with intrathoracic pressure during normal breathing, while positive pressure ventilation affects IAP directly [57]. Valsalva manoeuvers, such as coughing, sneezing, squatting, or singing loudly, increase IAP dramatically for short periods of time [12]. In conditions such as obesity or pregnancy, basic IAP may range from 10 to $15 \mathrm{mmHg}[18,39,40]$.

Intra-abdominal hypertension (IAH) is defined as a sustained IAP elevation equal to or above $12 \mathrm{mmHg}$, usually documented in three consecutive measurements taken at 4- to 6-h intervals. Since 2004, the World Society of the Abdominal Compartment Syndrome (WSACS, recently renamed Abdominal Compartment Society) has developed a cohesive approach to the management of IAH and ACS, fostered education and research, and developed consensus statements and definitions [20,35]. Recently the society changed its name to the Abdominal Compartment Society [Ki.]

While the impact of elevated IAP has been described anecdotally in neurological conditions, the anatomy and pathophysiology of the related vascular structures have not yet been described in detail. In this manuscript, we will focus on both issues and review the literature on the relevance and impact of elevated IAP in neurological and neurosurgical practice.

\section{Methods: search strategy and paper selection}

Relevant articles were identified by searching PubMed from 1918 to 2018 and also by screening the references of the identified articles.

The following search items were used: "Intra-abdominal pressure AND neurosurgery," "intra-abdominal pressure AND spine surgery," "intra-abdominal pressure AND TBI," "intra-abdominal pressure AND hydrocephalus," "intra-abdominal pressure AND IIH".

After the search by the first author, all literature was reviewed by the coauthors and supplemented with relevant articles. The coauthors are experts in various areas related to IAP: history, neuroanatomy, intensive care medicine, and neurosurgery.

\section{Historical perspective}

The relationship between the IAP and the intracranial pressure (ICP) has been suspected for more than 100 years.

The existence of both the cranial venous system and the vertebral venous system (VVS) was already known in the sixteenth century, but it was Breschet in 1828-1832 who published the first detailed drawings, accurately visualizing the multiple anastomoses c.q. the anatomical connections between the intracranial venous system and the VVS.
In 1940, the first of Batson's two landmark articles appeared, dealing with properties of the spinal veins. His radiological study provided an explanation for the spread of metastasis and infections through these vertebral veins, into the spine and the central nervous system [4], while bypassing both the liver and lungs [25]. Batson's drawing in 1957 illustrates the extent of the connections of the multiple veins of the valveless spinal epidural venous network. These veins are now known as Batson's veins (Fig. 1). His original paper from 1940 still is the most frequently cited in spinal oncology [16].

Multiple anatomical studies over the past century have shown that the cranial and vertebral venous system has connections to both the deep systemic, valved venous system, including the inferior and superior vena cava, to the valveless superficial veins in the face, head, and back and to the thoracoabdominal wall [4, 26, 30] (Fig. 2).

In 2000, Dwight Parkinson described the extradural neural axis compartment (EDNAC), which is characterized by valveless veins that allow blood to run freely in either direction between the orbit and the os coccygis [52]. Later, in 2006, Tobinick et al. introduced the term cerebrospinal venous system (CSVS), to emphasize the continuity/connectivity of the intracranial and the spinal venous networks. The first of the two main parts of this network are the intracranial veins. The second part consists of the vertebral venous system (Fig. 3) which courses along the entire length of the spine. The intracranial veins richly anastomose with the VVS in the suboccipital region, especially the suboccipital sinus. Caudally, the CSVS freely communicates with the sacral and pelvic veins and the prostatic venous plexus [48, 59]. However, we will continue to use the term EDNAC, since in recent literature, this was the first accurate description of this venous network.

\section{Anatomical considerations and pathophysiology}

The pivotal system responsible for the regulation of pressure within the spinal canal and partially within the intradural compartment seems to be the venous structures belonging to the extradural neural axis compartment. The vertebral venous system is a part of that structure and parallels, joins, and at the same time bypasses the longitudinal veins of the thoracoabdominal cavity. The VVS is connected with both the superior and the inferior vena cava by means of numerous connections with the intrathoracic (hemi)azygos venous system and the intra-abdominal lumbar veins. Also, numerous connections exist with the subcutaneous veins of the chest and the abdomen, the vertebral veins of the neck, and the sacral venous plexus.

Since the VVS is valveless, flow and the direction of flow depend (1) on pressure gradients between the IAP, 


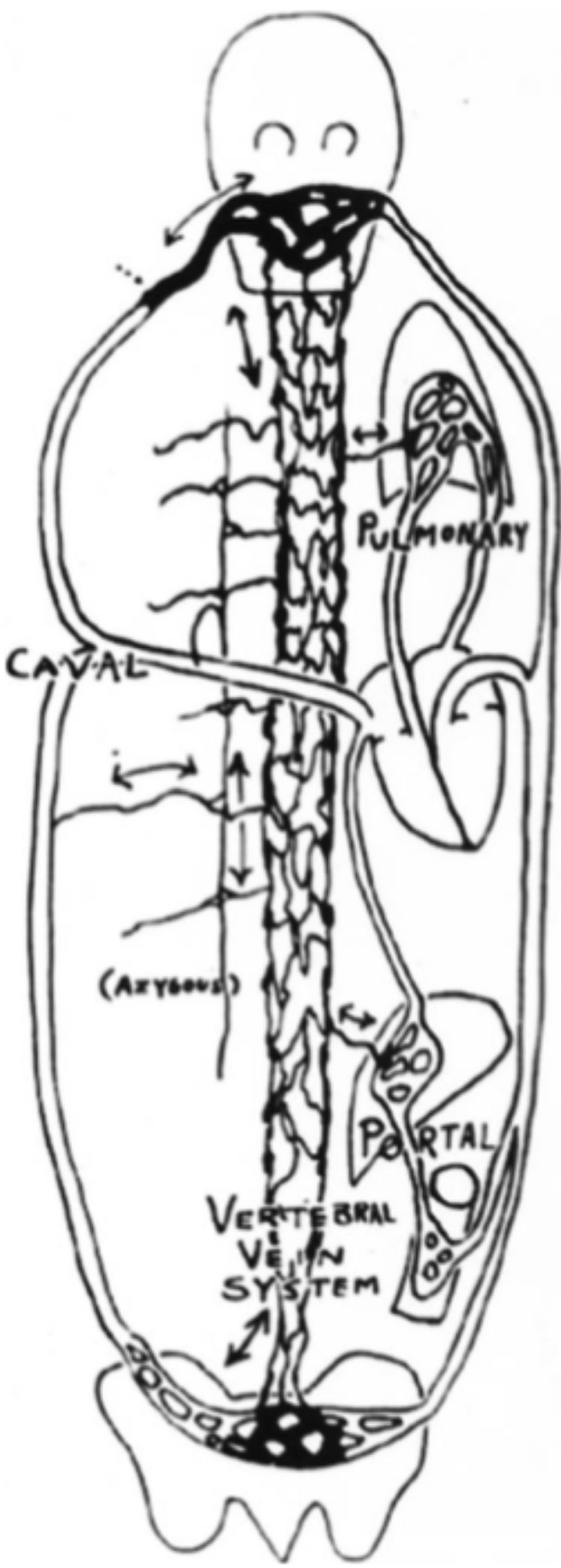

Fig. 1 Batson's 1940 drawing of the valveless pathways within and about the vertebral column

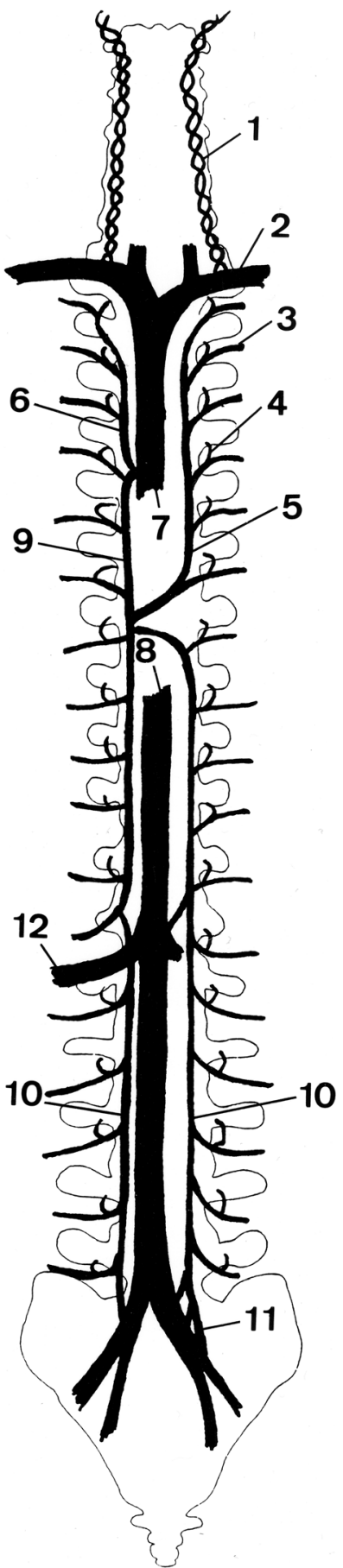

Fig. 2 Schematic representation of the connections of the vertebral venous system (VVS) with the vena cava system showing the vertebral vein (1), subclavian vein (2), segmental thoracic (intercostal) and lumbar veins (3), intervertebral vein (4), hemiazygos vein (5), internal thoracic vein (6), superior vena cava (7), inferior vena cava (8), azygos vein (9), ascending lumbar vein (10), sacral venous plexus (11), and the renal vein (12). Reproduced from Groen et al. [62] with permission from Lippincott Williams \& Wilkins

the intrathoracic pressure (ITP) and the pressure in the spinal canal which is largely determined by the ICP; and (2) on hydrostatic factors and gravitation forces that may occur with changing of posture or position (lying, sitting, standing). 


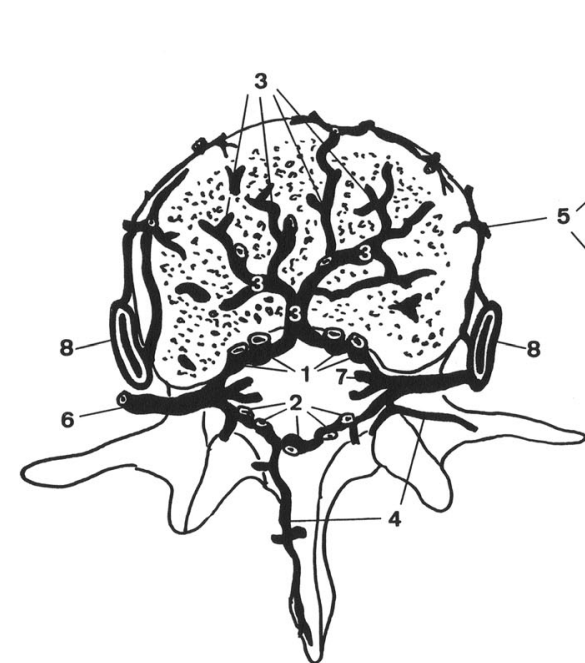

Fig. 3 Schematic representation of the vertebral venous system (VVS) at the lumbar area showing the anterior internal vertebral venous plexus (1), posterior internal vertebral venous plexus (2), basivertebral veins (3), posterior external vertebral venous plexus (4), anterior external vertebral

Morphological features that seem of the utmost importance are the fact (1) that the VVS has a large volume (probably 20 times larger than that of the contributing arteries [10]); (2) that it has numerous valveless connections with the cranial, spinal, thoracic, abdominal, and subcutaneous veins; and (3) that a significant part of this system is situated inside the rigid spinal canal (mass effect if congestions occurs [29, 50]).

Two important mechanisms are involved in the interaction between the abdominal compartment and the central nervous system. In the first mechanism, the VVS is the anatomical substrate for transmission of the IAP to the spinal canal and the cranium.

This valveless VVS, which allows bidirectional flow, is a huge reservoir for blood. Pressure change in one compartment of the human body and can thus shift venous blood to the other compartment. Epstein and colleagues described this as a largecapacity "venous lake," out of which blood may flow into the brain and spinal canal and into which blood may flow from the brain, depending on variations in posture and thoracic pressure or IAP [26].

Secondly, an increased IAP has an influence on the intrathoracic pressure (ITP). Cerebrospinal fluid (CSF) and the brain's venous drainage both leave the brain via the jugular veins and the VVS. Elevations in the IAP are transferred into the thoracic compartment, which in turn results in a back pressure on the jugular veins and decreases the drainage of the CSF and blood, leading to an increased ICP [56, 43] (Fig. 4).

Interaction between the abdomen and the central nervous system has been studied in humans and in animal models [17, 21]. The Monro-Kellie hypothesis states that the cranium is a rigid vault that contains brain tissue, CSF, and blood [61]. If one of the three components increases in size, the volume of

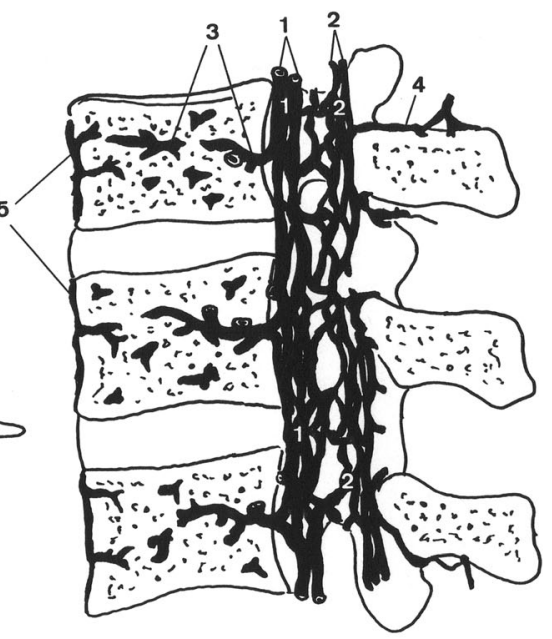

venous plexus (5), intervertebral vein (6), radicular vein (7), and the ascending lumbar vein (8). Reproduced from Groen et al. [62] with permission from Lippincott Williams \& Wilkins

the other two has to decrease, in order to maintain equilibrium and to prevent a raise of ICP. An increase in IAP (acute or chronic) will result in a subsequent increase of the intracranial volume of venous blood and can cause an increased ICP.

The relationship between IAP and ICP has not only been demonstrated by the study of Batson in 1940 but also by more recent and more modern techniques. As the optic nerve sheath (ONS) is part of the dura mater and the optic nerve is surrounded by CSF, a change in pressure within the subarachnoid space is detected by ultrasonography. An analysis of prospectively collected data of patients who underwent laparoscopic procedures showed that an acute elevation in IAP significantly increased the optic nerve sheath diameter (ONSD). The changes in the ONSD reflect a temporary and reversible increase in ICP [23]. Recent literature shows an increase in the number of publications reporting total perioperative visual loss (POVL) in healthy patients after elective laparoscopic surgery [53].

\section{IAP measurement technique}

The intravesicular IAP measurement is convenient and is considered the gold standard [46, 58]. IAP is the pressure concealed within the abdominal cavity as defined superiorly by the diaphragm, anteriorly and posteriorly by the abdominal wall, and inferiorly by the pelvic floor. In general, the abdominal compartment transduces pressure evenly throughout the cavity. IAP can thus be measured via every cavity within this defined region (intra-gastric, inferior vena cava, rectal, vaginal). Femoral vein pressure cannot be used as a surrogate measure of IAP [15]. 


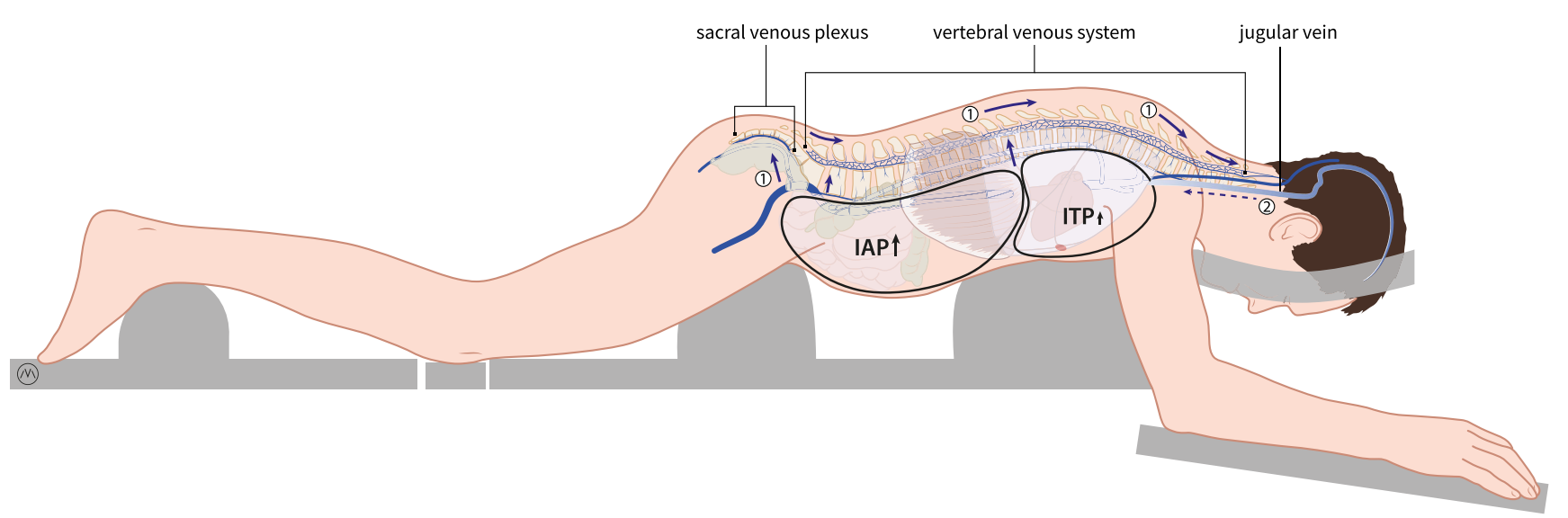

Fig. 4 Schematic drawing illustrating the concept of the two pathways. In the first pathway, an increase in IAP can cause backflow through the sacral venous plexus and the vertebral venous into the spinal canal. This can cause congestion of venous blood in the spinal canal and can cause flow of venous blood into the brain. In the second pathway, an

Conditions for a reproducible intravesicular IAP measurement are measured at end-expiration; performed in the supine position; zeroed at the iliac crest in the mid-axillary line, using a priming volume in the bladder of $<25 \mathrm{~mL}$ of saline; measured $30-60 \mathrm{~s}$ after instillation to allow for bladder detrusor muscle; and measured in the absence of active abdominal muscle contractions. Values need to be expressed in millimeters of mercury $\left(1 \mathrm{mmHg}=1.36 \mathrm{cmH}_{2} \mathrm{O}\right)$. In a prospective comparative study, Al-Abassi et al. showed that intra-bladder pressure measurement is a simple, minimally invasive method that may reliably estimate the IAP in patients placed in supine position [2].

Body position can affect IAP. In a multicenter analysis of different body positions, Cheatham et al. found that mean IAP values were significantly different at each head of bed position [7]. Even the position of the transducer located in the midaxillary line or located at the level of the symphysis pubis can cause a bias [19].

Both of these studies emphasize the importance of a standardized approach to IAP measurement to ensure the reproducibility of the results.

In the future, new techniques may become available using cost-effective solid-state pressure transducers, inserted via the bladder or stomach or by ingestion of wireless capsules, allowing continuous monitoring of IAP [58].

\section{IAP and neurosurgical procedures}

In neurosurgical operating procedures, the influence of posture on ICP is well-known. In the early days, when surgery of the nervous system was developing, one of the main factors that complicated craniotomy was the inability to control ICP. Brain prolapse and uncontrollable swelling in awake patients was the reason that brain surgery results were disappointing, increase in IAP can cause an increase in ITP (intrathoracic pressure) which in turn results in a back pressure on the jugular veins and decreases the drainage of the CSF and the venous blood. Drawing made by Medical Visuals in collaboration with Dr. Paul Depauw

and in the absence of anesthesiology support, the associated surgical mortality was frustratingly high, especially in posterior fossa surgery [6].

\section{IAP and spine surgery or posterior fossa surgery: the prone position}

Nowadays, with excellent anesthesiologic support and sophisticated neurosurgical equipment, intracranial and spinal surgery has become safe and controllable. However, correct positioning of the patient is key for a smooth and uncomplicated operative procedure, especially with respect to cerebral venous drainage. With a patient in prone position (for spine surgery or posterior fossa surgery), a free-hanging abdomen is mandatory to prevent venous congestion of the operative field $[1,8]$. Prior to surgery, it is verified manually whether the abdomen is free-hanging via "palpation of the belly to exclude any external pressure." In order to secure an uncompromised venous return, the use of thoracolumbar supports has become standard practice in neurosurgery (Fig. 4). Although not generally accepted in the intensive care (ICU), these supports also can be beneficial for lowering IAP in adult patients with respiratory distress syndrome (ARDS) who require ventilation in the prone position $[3,36,45,54]$.

One of the implications of inadequate positioning during spine surgery in the prone position is the increased blood loss associated with the higher IAP values that were described in some studies. A rise in IAP can cause venous congestion in the pelvis and abdomen. This may lead to backflow of venous blood into large valveless VVS, which can result in venous congestion in the rigid spinal canal, which makes spinal surgery complicated $[8,51]$ (Fig. 4 ).

The study by Han et al. was the first prospective study to show the effect of BMI on IAP and intra-operative blood loss 
during spinal surgery. Besides this cumbersome blood loss, the visual operating field is obscured, making microsurgery a more difficult and frequently a higher complexity procedure because of the risk of damaging neurological structures and creating temporary or permanent postoperative loss of function.

Another consequence of inadequate positioning can be brain swelling during posterior fossa surgery or supratentorial craniotomy in the prone position. As mentioned earlier, raised IAP causes a rise of the intrathoracic pressure. This causes an increase in back pressure in the jugular veins and decreased drainage of venous blood and CSF (Fig. 5).

However, it is clearly not yet common knowledge that venous congestion in the spinal canal is a problem in surgery in prone position and that this problem involves the IAP. In a review by Chui et al. about the prevention of complications related to prone positioning during spinal surgery, the reviewers did not consider the importance of a free abdomen to reduce the incidence of postoperative visual loss was not considered $[8,22]$.

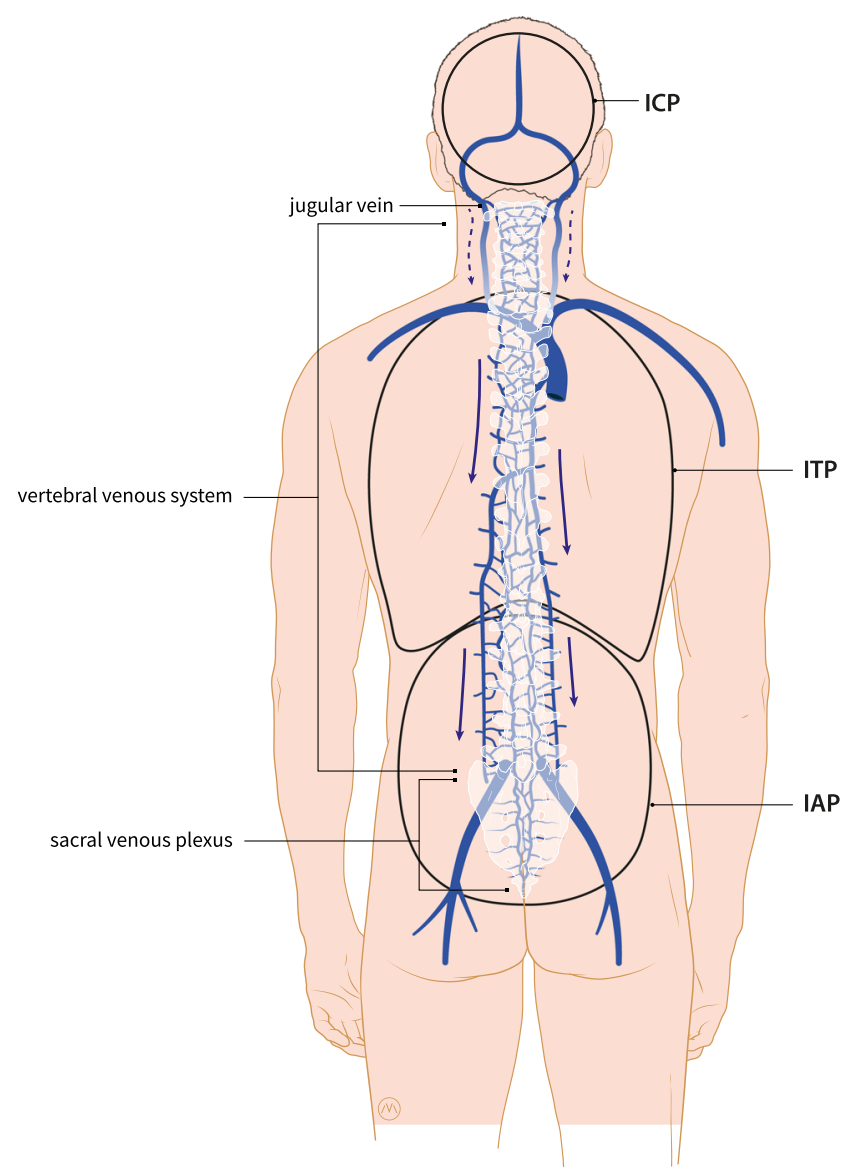

Fig. 5 Schematic drawing illustrating the preferred venous outflow of the brain in the upright position and the possible influence of the IAP and ITP on this flow. The blue arrow shows the preferred outflow in the valveless vertebral venous system (VVS). The dashed arrow shows the reduced flow through the jugular venous system in the upright position. Drawing made by Medical Visuals in collaboration with Dr. Paul Depauw

\section{The effect of IAH on internal shunting of CSF in case of hydrocephalus}

In the neurosurgical community, IAP is regarded as a negligible variable when considering the use of a ventriculoperitoneal shunt for treating hydrocephalus. It is a general misconception in the neurosurgical community that IAP is around $0 \mathrm{mmHg}$ and therefore does not interfere with CSF drainage into the peritoneal cavity.

A study performed by Sahuquillo et al. on 60 patients requiring a ventriculoperitoneal shunt evaluated the relationship between body mass index (BMI) and IAP and provided data to estimate IAP in order to help neurosurgeons with the selection of the appropriate shunt. IAP was measured through an intraperitoneal catheter during shunt surgery. The authors concluded that in obese and overweight patients, neurosurgeons should take IAP into account when selecting both the most adequate differential pressure valve and the distal cavity to place the distal catheter. IAH could be a reason to choose another distal cavity, for example the pleural cavity $[11,55]$.

Therefore, in the event of neurologic deterioration in patients with a pre-existing ventriculoperitoneal shunt during critical illness, IAP should be monitored and IAH should be treated promptly. IAP should also be monitored in critically ill, sedated, and mechanically ventilated patients with a ventriculoperitoneal shunt, since neurologic examination is unreliable in these circumstances.

Raised IAP due to constipation, ileus, or small-bowel obstruction has also been reported to play a role in malfunctioning ventriculoperitoneal shunts in patients with hydrocephalus [44].

\section{IAP in neurological conditions: the effect of the IAP on the ICP}

\section{IAP and TBI}

Various case reports have described raised ICP following abdominal closure after laparotomy in polytrauma patient. A patient whose acute subdural hematoma was removed in combination with a splenectomy for trauma-developed acute bleeding from his right transverse sinus and brain herniation as the abdomen was closed, indicating a rise in venous pressure [31].

The first well-conducted clinical study evaluating the relationship between IAP and ICP in 15 patients with traumatic brain injury was published by Citerio et al. in 2001 [9]. They conducted a prospective non-randomized observational study systematically measuring the effect of increased IAP, by positioning a soft $15-\mathrm{L}$ bag of water on the patient's abdomen. Obviously, patients could only be included in this study after the acute phase of their injury, when no intracranial hypertension was present. The authors found that placing a weight on 
the patient's abdomen generated a significant increase in IAP and a concomitant and rapid increase in ICP, central venous pressure (CVP), and jugular bulb pressure (IJP). All these values reached a plateau within seconds and remained increased until weight removal.

A number of publications reported decompressive laparotomy (DL) as a last resort to decrease otherwise untreatable intracranial hypertension after TBI. In one series, abdominal fascia release resulted in the decrease of ICP in 11 out of 17 patients. All 11 patients survived [34].

In a study by Neville et al., 15 patients with normal opening pressures on lumbar puncture and referred for CSF analysis were asked to artificially increase their IAP through a Valsalva maneuver [49]. All were able to elevate their CSF pressure to values above $25 \mathrm{cmH}_{2} \mathrm{O}$, and one patient even achieved a value of $47 \mathrm{cmH}_{2} \mathrm{O}$. The authors were prompted to perform this study after the observation that patients were referred for fundoscopy due to increased CSF pressure while they had no symptoms of intracranial hypertension.

In a series of 102 patients who sustained blunt brain injury, Scalea et al. evaluated the serial application of decompressive craniectomy (DC) and decompressive laparotomy (DL) to treat multicompartment syndrome (MCS) and to lower ICP; $24 \%$ of the patients required both interventions. Fifteen patients had DC before DL and nine had DL before DC. The mean time between DC and DL was $3.4 \pm 6$ days. Mean ICP decreased significantly after both DC and DL $(p<0.05)$ [56].

In a recent review, Lauerman et al. described the pathophysiology of a multicompartment syndrome (MCS) and current treatment considerations for patients with TBI given the effect of MCS. In MCS, intracranial, intrathoracic, and intraabdominal compartment pressures are interrelated. The authors concluded that TBI care should include ICP control as well as minimization of intrathoracic and intra-abdominal pressure as far as clinically possible [38].

Another indication of the link between cerebral venous outflow and ICP is the beneficial effect on a raised ICP in TBI that is achieved by elevating the head of the bed [56]. Another important (iatrogenic) factor in TBI is fluid management. For instance, fluid therapy to support cerebral perfusion pressure (CPP) may cause retroperitoneal and visceral edema, increasing IAP, which in turn can increase ICP. Ventilatory manoeuvers for treating respiratory failure (e.g., recruitment) may increase intrathoracic pressure, limiting venous return, and thus increasing ICP and decreasing CPP [56]. All these findings support the claim that a more profound understanding and appreciation of the role of the venous system in neurocritical care is vital [61].

\section{IAP and IIH}

Idiopathic intracranial hypertension (IIH) is characterized by an elevation of intracranial pressure (ICP). In the primary form, there is no identifiable cause. IIH is a disorder that mainly affects obese women of childbearing age. Its prevalence has been estimated to lie between 0.5 and 2 per 100,000 of the general population. Clinical symptoms include headache; visual disturbances due to papilloedema and, less frequently, olfactory dysfunction; uni- or bilateral pulsatile tinnitus; diplopia due to sixth nerve palsy; and cognitive dysfunction [32]. Obesity is a consistent risk factor for the development of IIH [13, 33, 40]. Despite the association between IIH and an obese phenotype, the pathological mechanisms tying the two together are unclear. IIH is a rare disorder, while obesity is common [47].

The jugular venous system is commonly recognized as the main route of venous efflux from the brain. However, the jugular venous system has important flow limitations with changes in posture as described earlier in the pathophysiology [28]. A volume capacity of up to $1000 \mathrm{~mL}$ has been calculated for the extrajugular venous system, which could be sufficient to take over the entire venous drainage of the brain [24, 26]. In 1970, Epstein and colleagues provided scientific evidence to support this hypothesis by demonstrating that when the sagittal sinus was injected with contrast media in rhesus monkeys in the upright position, the vertebral venous system was the main route of venous efflux from the brain, and the venous vertebral system continued to be an important venous outflow tract even in the supine position. They suggested that the vertebral venous plexus may act as a siphon, facilitating the flow of blood across the brain in the upright position [26].

Other studies confirmed that the anastomoses between the cranial and vertebral portions of the CSVS appear to serve an important function in providing pressure homeostasis to the intracranial venous system with changes in posture $[27,28$, 60]. A systematic ultrasound analysis by Doepp described the variations of the cerebral venous drainage in the horizontal body position in healthy subjects and found the expected predominant jugular drainage in $72 \%$. However, in $22 \%$, the jugular equaled the extra-jugular drainage, and in $6 \%$, the extra-jugular drainage was the major path of cerebral venous outflow [24].

Besides the anatomical variations of cerebral venous drainage, there is also a variation in abdominal compliance [5]. Abdominal compliance is defined as a measure of the ease of abdominal expansion, which is determined by the elasticity of the abdominal wall and the diaphragm $[37,42]$. In case of a low abdominal compliance, a slight increase in intra-abdominal volume (and thus in IAP) could have a greater impact on ICP [41].

The balance between cerebral blood inflow and outflow is vital in maintaining normal ICP. Restrictions in venous outflow, for example due to a raised IAP, can be as important as mass accumulation within the cranium, if not more so [61] (Fig. 5).

The increased IAP in obese patients can thus influence ICP via the two pathways described in this literature review. The relationship between obesity and the onset of IIH is unclear for many reasons: first, there are many anatomical variants of 
venous drainage; second, there are differences in abdominal compliance between patients; and last, it is unclear by which pathway IAP has the most influence on ICP [61].

\section{Conclusions}

The IAP is an important physiological parameter in neurosurgery and neurology. It has a close relationship with the ICP, and current evidence supports the concept that there are two pathways by which the IAP can be transmitted to the central nervous system. One pathway is by backflow through the venous plexus of the spinal canal and the intracranial veins. This valveless venous plexus provides a direct anatomic route from the pelvis to the eyes and the brain, and vice versa. This is a route with numerous anastomoses to the systemic venous circulation, including the venous circulation of the lungs, the renal veins, and the veins of the breasts. The second pathway is a direct effect via an increase in IAP, which causes a cranial excursion of the diaphragm. The elevated intrathoracic pressure and augmented central venous pressure causes a decrease in venous drainage from the central nervous system via the jugular system.

Current evidence suggests that increased IAP may play an important role during neurosurgical procedures in patients suffering from IIH or TBI and during hydrocephalus therapy. IAP measurement could provide relevant information to improve the safety of surgical procedures in spine surgery and posterior fossa surgery. Furthermore, it could optimize the treatment for IIH, TBI, and hydrocephalus. However, more prospective research in this field is needed.

\section{Compliance with ethical standards}

Conflict of interest The authors declare that they have no conflict of interest.

Ethical approval This article does not contain any studies on human participants performed by any of the authors.

Open Access This article is distributed under the terms of the Creative Commons Attribution 4.0 International License (http:// creativecommons.org/licenses/by/4.0/), which permits unrestricted use, distribution, and reproduction in any medium, provided you give appropriate credit to the original author(s) and the source, provide a link to the Creative Commons license, and indicate if changes were made.

\section{References}

1. Akinci IO, Tunali U, Kyzy AA, Guresti E, Sencer A, Karasu A, Telci L (2011) Effects of prone and jackknife positioning on lumbar disc herniation surgery. J Neurosurg Anesthesiol 23(4):318-322

2. Al-Abassi AA, Al Saadi AS, Ahmed F (2018) Is intra-bladder pressure measurement a reliable indicator for raised intra-abdominal pressure? A prospective comparative study. BMC Anesthesiol 18(1):69

3. Ball CG, Kirkpatrick AW, Pelosi P, De Waele J (2010) Intraabdominal hypertension, prone ventilation, and abdominal suspension. J Trauma 68(4):1017

4. Batson OV (1940) The function of the vertebral veins and their role in the spread of metastases. Ann Surg 112(1):138-149

5. Blaser AR, Björck M, De Keulenaer B, Regli A (2015) Abdominal compliance: a bench-to-bedside review. J Trauma Acute Care Surg 78(5):1044-1053

6. Carson LV, Goodrich JT, Prestigiacomo CJ (2014) History of craniotomy, cranioplasty, and perioperative care. Neurosurg Focus 36(4) Introduction

7. Cheatham ML, De Waele JJ, De Laet I, De Keulenaer B, Widder S, Kirkpatrick AW, Cresswell AB, Malbrain M, Bodnar Z, MejiaMantilla JH, Reis R, Parr M, Schulze R, Puig S, WorldSOTACSWSACSCTWG (2009) The impact of body position on intra-abdominal pressure measurement: a multicenter analysis. Crit Care Med 37(7):2187-2190

8. Chui J, Craen RA (2016) An update on the prone position: continuing professional development. Can J Anaesth 63(6):737-767

9. Citerio G, Vascotto E, Villa F, Celotti S, Pesenti A (2001) Induced abdominal compartment syndrome increases intracranial pressure in neurotrauma patients: a prospective study. Crit Care Med 29(7): $1466-1471$

10. Clemens HJ, Vogelsang H (1970) Transosseous phlebography of the vertebral column and spinal canal. Morphological and clinical aspects. Verh Anat Ges 64:179-180

11. Craven C, Asif H, Farrukh A, Somavilla F, Toma AK, Watkins L (2017) Case series of ventriculopleural shunts in adults: a singlecenter experience. J Neurosurg 126(6):2010-2016

12. Cutrer FM, De Lange J (2014) Cough, exercise, and sex headaches. Neurol Clin 32(2):433-450

13. Daniels AB, Liu GT, Volpe NJ, Galetta SL, Moster ML, Newman NJ, Biousse V, Lee AG, Wall M, Kardon R, Acierno MD, Corbett JJ, Maguire MG, Balcer LJ (2007) Profiles of obesity, weight gain, and quality of life in idiopathic intracranial hypertension (pseudotumor cerebri). Am J Ophthalmol 143(4):635-641

14. De Keulenaer BL, De Waele JJ, Powell B, Malbrain ML (2009) What is normal intra-abdominal pressure and how is it affected by positioning, body mass and positive end-expiratory pressure. Intensive Care Med 35(6):969-976

15. De Keulenaer BL, Regli A, Dabrowski W, Kaloiani V, Bodnar Z, Cea JI, Litvin AA, Davis WA, Palermo AM, De Waele JJ, Malbrain ML (2011) Does femoral venous pressure measurement correlate well with intrabladder pressure measurement? A multicenter observational trial. Intensive Care Med 37(10):1620-1627

16. De la Garza-Ramos R, Benvenutti-Regato M, Caro-Osorio E (2016) The 100 most-cited articles in spinal oncology. J Neurosurg Spine 24(5):810-823

17. De laet I, Citerio G, Malbrain ML (2007) The influence of intraabdominal hypertension on the central nervous system: current insights and clinical recommendations, is it all in the head. Acta Clin Belg 62(Suppl 1):89-97

18. De Waele JJ, Cheatham ML, Malbrain ML, Kirkpatrick AW, Sugrue M, Balogh Z, Ivatury R, De Keulenaer B, Kimball EJ (2009) Recommendations for research from the international conference of experts on intra-abdominal hypertension and abdominal compartment syndrome. Acta Clin Belg 64(3):203-209

19. De Waele JJ, De Laet I, De Keulenaer B, Widder S, Kirkpatrick AW, Cresswell AB, Malbrain M, Bodnar Z, Mejia-Mantilla JH, Reis R, Parr M, Schulze R, Compano S, Cheatham M (2008) The effect of different reference transducer positions on intra-abdominal pressure measurement: a multicenter analysis. Intensive Care Med 34(7):1299-1303 
20. De Waele JJ, Malbrain ML, Kirkpatrick AW (2015) The abdominal compartment syndrome: evolving concepts and future directions. Crit Care 19:211

21. Deeren DH, Dits H, Malbrain ML (2005) Correlation between intra-abdominal and intracranial pressure in nontraumatic brain injury. Intensive Care Med 31(11):1577-1581

22. Dip F, Nguyen D, Rosales A, Sasson M, Lo Menzo E, Szomstein S, Rosenthal R (2016) Impact of controlled intraabdominal pressure on the optic nerve sheath diameter during laparoscopic procedures. Surg Endosc 30(1):44-49

23. Dip F, Nguyen D, Sasson M, Lo Menzo E, Szomstein S, Rosenthal R (2016) The relationship between intracranial pressure and obesity: an ultrasonographic evaluation of the optic nerve. Surg Endosc 30(6):2321-2325

24. Doepp F, Schreiber SJ, von Münster T, Rademacher J, Klingebiel R, Valdueza JM (2004) How does the blood leave the brain? A systematic ultrasound analysis of cerebral venous drainage patterns. Neuroradiology 46(7):565-570

25. Doepp F, Schreiber SJ, Wandinger KP, Trendelenburg G, Valdueza JM (2006) Multiple brain abscesses following surgical treatment of a perianal abscess. Clin Neurol Neurosurg 108(2):187-190

26. Epstein HM, Linde HW, Crampton AR, Ciric IS, Eckenhoff JE (1970) The vertebral venous plexus as a major cerebral venous outflow tract. Anesthesiology 32(4):332-337

27. Gehlen M, Kurtcuoglu V, Schmid Daners M (2017) Is posturerelated craniospinal compliance shift caused by jugular vein collapse? A theoretical analysis. Fluids Barriers CNS 14(1):5

28. Gisolf J, van Lieshout JJ, van Heusden K, Pott F, Stok WJ, Karemaker JM (2004) Human cerebral venous outflow pathway depends on posture and central venous pressure. J Physiol 560(Pt 1):317-327

29. Groen RJ, Batchelor DA, Hoogland PV (2000) RE: congenital dilatation of the cervical epidural venous plexus: neuroradiology and endovenous management. Minim Invasive Neurosurg 43(2): $109-110$

30. Groen RJ, Groenewegen HJ, van Alphen HA, Hoogland PV (1997) Morphology of the human internal vertebral venous plexus: a cadaver study after intravenous araldite CY 221 injection. Anat Rec 249(2):285-294

31. Hendrickson S, Chacko L, Wilson MH (2015) Raised intracranial pressure following abdominal closure in a polytrauma patient. JRSM Open 6(1):2054270414565958

32. Hoffmann J, Mollan SP, Paemeleire K, Lampl C, Jensen RH, Sinclair AJ (2018) European headache federation guideline on idiopathic intracranial hypertension. J Headache Pain 19(1):93

33. Holodinsky JK, Roberts DJ, Ball CG, Blaser AR, Starkopf J, Zygun DA, Stelfox HT, Malbrain ML, Jaeschke RC, Kirkpatrick AW (2013) Risk factors for intra-abdominal hypertension and abdominal compartment syndrome among adult intensive care unit patients: a systematic review and meta-analysis. Crit Care 17(5):R249

34. Joseph DK, Dutton RP, Aarabi B, Scalea TM (2004) Decompressive laparotomy to treat intractable intracranial hypertension after traumatic brain injury. J Trauma 57(4):687-693 discussion 693

35. Kirkpatrick AW, De Waele JJ, De Laet I, De Keulenaer BL, D’Amours S, Björck M, Balogh ZJ, Leppäniemi A, Kaplan M, Chiaka Ejike J, Reintam Blaser A, Sugrue M, Ivatury RR, Malbrain ML (2015) WSACS-the abdominal compartment society. A society dedicated to the study of the physiology and pathophysiology of the abdominal compartment and its interactions with all organ systems. Anaesthesiol Intensive Ther 47(3):191-194

36. Kirkpatrick AW, Pelosi P, De Waele JJ, Malbrain ML, Ball CG, Meade MO, Stelfox HT, Laupland KB (2010) Clinical review: Intra-abdominal hypertension: does it influence the physiology of prone ventilation. Crit Care 14(4):232
37. Kirkpatrick AW, Roberts DJ, De Waele J, Jaeschke R, Malbrain ML, De Keulenaer B, Duchesne J, Bjorck M, Leppaniemi A, Ejike JC, Sugrue M, Cheatham M, Ivatury R, Ball CG, Reintam Blaser A, Regli A, Balogh ZJ, D’Amours S, Debergh D, Kaplan M, Kimball E, Olvera C, Pediatric GS-CFTWSOTACS (2013) Intraabdominal hypertension and the abdominal compartment syndrome: updated consensus definitions and clinical practice guidelines from the World Society of the Abdominal Compartment Syndrome. Intensive Care Med 39(7):1190-1206

38. Lauerman MH, Stein DM (2014) Multicompartment management of patients with severe traumatic brain injury. Curr Opin Anaesthesiol 27(2):219-224

39. Lee RK (2012) Intra-abdominal hypertension and abdominal compartment syndrome: a comprehensive overview. Crit Care Nurse 32(1):19-31

40. Malbrain ML, De Keulenaer BL, Oda J, De Laet I, De Waele JJ, Roberts DJ, Kirkpatrick AW, Kimball E, Ivatury R (2015) Intraabdominal hypertension and abdominal compartment syndrome in burns, obesity, pregnancy, and general medicine. Anaesthesiol Intensive Ther 47(3):228-240

41. Malbrain ML, De Laet I, De Waele JJ, Sugrue M, Schachtrupp A, Duchesne J, Van Ramshorst G, De Keulenaer B, Kirkpatrick AW, Ahmadi-Noorbakhsh S, Mulier J, Pelosi P, Ivatury R, Pracca F, David M, Roberts DJ (2014) The role of abdominal compliance, the neglected parameter in critically ill patients - a consensus review of 16. Part 2: measurement techniques and management recommendations. Anaesthesiol Intensive Ther 46(5):406-432

42. Malbrain ML, Roberts DJ, De Laet I, De Waele JJ, Sugrue M, Schachtrupp A, Duchesne J, Van Ramshorst G, De Keulenaer B, Kirkpatrick AW, Ahmadi-Noorbakhsh S, Mulier J, Ivatury R, Pracca F, Wise R, Pelosi P (2014) The role of abdominal compliance, the neglected parameter in critically ill patients - a consensus review of 16. Part 1: definitions and pathophysiology. Anaesthesiol Intensive Ther 46(5):392-405

43. Malbrain ML, Roberts DJ, Sugrue M, De Keulenaer BL, Ivatury R, Pelosi P, Verbrugge F, Wise R, Mullens W (2014) The polycompartment syndrome: a concise state-of-the-art review. Anaesthesiol Intensive Ther 46(5):433-450

44. Martínez-Lage JF, Martos-Tello JM, Ros-de-San Pedro J, Almagro MJ (2008) Severe constipation: an under-appreciated cause of VP shunt malfunction: a case-based update. Childs Nerv Syst 24(4): 431-435

45. Michelet P, Roch A, Gainnier M, Sainty JM, Auffray JP, Papazian L (2005) Influence of support on intra-abdominal pressure, hepatic kinetics of indocyanine green and extravascular lung water during prone positioning in patients with ARDS: a randomized crossover study. Crit Care 9(3):R251-R257

46. Milanesi R, Caregnato RC (2016) Intra-abdominal pressure: an integrative review. Einstein (Sao Paulo) 14(3):423-430

47. Mollan SP, Ali F, Hassan-Smith G, Botfield H, Friedman DI, Sinclair AJ (2016) Evolving evidence in adult idiopathic intracranial hypertension: pathophysiology and management. J Neurol Neurosurg Psychiatry 87(9):982-992

48. Nathoo N, Caris EC, Wiener JA, Mendel E (2011) History of the vertebral venous plexus and the significant contributions of Breschet and Batson. Neurosurgery 69(5):1007-1014 discussion 1014

49. Neville L, Egan RA (2005) Frequency and amplitude of elevation of cerebrospinal fluid resting pressure by the Valsalva maneuver. Can J Ophthalmol 40(6):775-777

50. Oterdoom DL, de Jong BM, Hoogland PV, Groen RJ (2007) Transient cauda equina compression syndrome and headache caused by internal vertebral venous plexus engorgement in a teenage female with vena cava inferior agenesis and iliac vein thrombosis. J Neurol Neurosurg Psychiatry 78(11):1283-1284 
51. Park CK (2000) The effect of patient positioning on intraabdominal pressure and blood loss in spinal surgery. Anesth Analg 91(3):552557

52. Parkinson D (2000) Extradural neural axis compartment. J Neurosurg 92(4):585-588

53. Pinkney TD, King AJ, Walter C, Wilson TR, Maxwell-Armstrong C, Acheson AG (2012) Raised intraocular pressure (IOP) and perioperative visual loss in laparoscopic colorectal surgery: a catastrophe waiting to happen? A systematic review of evidence from other surgical specialities. Tech Coloproctol 16(5):331-335

54. Putensen C (2005) Prone position in mechanically ventilated patients - the hard or the soft way. Crit Care 9(3):253-254

55. Sahuquillo J, Arikan F, Poca MA, Noguer M, Martinez-Ricarte F (2008) Intra-abdominal pressure: the neglected variable in selecting the ventriculoperitoneal shunt for treating hydrocephalus. Neurosurgery 62(1):143-149 discussion 149

56. Scalea TM, Bochicchio GV, Habashi N, McCunn M, Shih D, McQuillan K, Aarabi B (2007) Increased intra-abdominal, intrathoracic, and intracranial pressure after severe brain injury: multiple compartment syndrome. J Trauma 62(3):647-656 discussion 656

57. Soler Morejón CD, Tamargo Barbeito TO (2012) Effect of mechanical ventilation on intra-abdominal pressure in critically ill patients without other risk factors for abdominal hypertension: an observa- tional multicenter epidemiological study. Ann Intensive Care 2(Suppl 1):S22

58. Sugrue M, De Waele JJ, De Keulenaer BL, Roberts DJ, Malbrain ML (2015) A user's guide to intra-abdominal pressure measurement. Anaesthesiol Intensive Ther 47(3):241-251

59. Tobinick E, Vega CP (2006) The cerebrospinal venous system: anatomy, physiology, and clinical implications. MedGenMed $8(1): 53$

60. Valdueza JM, von Münster T, Hoffman O, Schreiber S, Einhäupl KM (2000) Postural dependency of the cerebral venous outflow. Lancet 355(9199):200-201

61. Wilson MH (2016) Monro-Kellie 2.0: the dynamic vascular and venous pathophysiological components of intracranial pressure. $\mathrm{J}$ Cereb Blood Flow Metab 36(8):1338-1350

62. Groen RJM et al (2004) An anatomical and pathological considerations in percutaneous vertebroplasty and kyphoplasty: a reappraisal of the vertebral venous system. Spine 29(13):1465-1471

Publisher's note Springer Nature remains neutral with regard to jurisdictional claims in published maps and institutional affiliations. 